\title{
Insensitivity to the Fungicide Fosetyl-Aluminum in California Isolates of the Lettuce Downy Mildew Pathogen, Bremia lactucae
}

\author{
Sarah Brown, Department of Vegetable Crops, University of California, Davis, CA 95616; Steven T. Koike, Univer- \\ sity of California Cooperative Extension, Salinas, CA 93901; Oswaldo E. Ochoa, Department of Vegetable Crops, \\ University of California, Davis, CA 95616; Frank Laemmlen, University of California Cooperative Extension, \\ Santa Maria, CA 93455; and Richard W. Michelmore, Department of Vegetable Crops, University of California, \\ Davis, CA 95616
}

\begin{abstract}
Brown, S., Koike, S. T., Ochoa, O. E., Laemmlen, F., and Michelmore, R. W. 2004. Insensitivity to the fungicide fosetyl-aluminum in California isolates of the lettuce downy mildew pathogen, Bremia lactucae. Plant Dis. 88:502-508.

Lettuce downy mildew, caused by Bremia lactucae, is the most important foliar disease of lettuce in California. In recent years, there were apparent failures of fungicides containing fosetylaluminum (Aliette) to control downy mildew in commercial lettuce fields in California. Consequently, we characterized 134 isolates collected over 2 years from throughout the coastal growing areas of California for insensitivity to the fungicides fosetyl-aluminum and maneb, pathotype, and mating type. Tests using seedlings in controlled growth room conditions demonstrated the widespread occurrence of insensitivity to fosetyl-aluminum in California populations of $B$. lactucae. Fifty percent of the isolates assayed sporulated profusely in the presence of fosetylaluminum applied at rates twice the normal field dosage, and an additional $40 \%$ showed moderate sporulation at this rate. Fosetyl-aluminum-insensitive isolates were detected from all regions sampled. Insensitivity was also observed in multiple pathotypes. Insensitivity was not complete, however, because quantitative analysis of the number of lesions on older plants revealed that applications of fosetyl-aluminum could reduce the levels of disease by $50 \%$. Therefore, while fosetyl-aluminum may have utility under low disease pressure in the field, other control measures are required to provide control under conditions favorable to the disease.
\end{abstract}

Additional keywords: Lactuca sativa, Nutri-Phite, phosphite, phosphonate

Lettuce (Lactuca sativa) is a major crop in California. Several different types are grown on over 76,000 ha with a gross value of $\$ 1.2$ billion (1). Lettuce is cultivated as extensive monocultures with multiple crop cycles per year. There are several diseases that threaten lettuce production in California, of which downy mildew is the most serious (10). Lettuce downy mildew is a regular problem in California, particularly in the coastal summer production areas of the Salinas and Santa Maria valleys. Control strategies involve the use of resistant cultivars $(7,20)$ and fungicide applications (34) that are based on information from genetic analysis of variation in the pathogen (43), epidemiological studies (4042), and disease prediction systems (39).

Since 1982, isolates of Bremia lactucae, the causal agent of lettuce downy mildew,

Corresponding author: R. W. Michelmore E-mail: rwmichelmore@ucdavis.edu

Major contributions were made by both the first and second authors; therefore they should be considered joint first authors.

Accepted for publication 22 December 2003.

Publication no. D-2004-0308-02R

(C) 2004 The American Phytopathological Society have been surveyed for virulence, mating type, and metalaxyl (Ridomil 2E, Syngenta) sensitivity $(31,32,43)$. Until 1991 , the majority of isolates analyzed from the major growing areas could be grouped into one of four pathotypes with subgroups that had been generated by asexual variation (19). However, over the past 10 years, the situation has become increasingly complex; many isolates were detected that did not fit the major pathotype pattern, and isolates with novel pathotypes have been detected (unpublished data). This increase in variability may have been the result of the increased diversity of lettuce cultivars being grown and the lack of metalaxyl applications in the spring, allowing the growth of both metalaxyl sensitive as well as insensitive isolates. In addition, isolates of the $\mathrm{B}_{1}$ mating type were occasionally detected in commercial fields, where $\mathrm{B}_{2}$ has been the prevalent mating type in recent years. If $B$. lactucae in California is in transition from a predominantly asexual to a sexual population, there will be an increase in genetic variability as well as a probable increase in the prevalence and earliness of epidemics, making the disease more difficult to control.

The pathogen has adapted to each genetic and fungicidal control measure as it was introduced, and consequently downy mildew remains problematic in California. In the mid-1980s, an asexual change in the pathogen rendered the resistance gene Dml ineffective; this resulted in several cultivars that had previously been resistant in California becoming susceptible (43). When first introduced commercially, the fungicide metalaxyl provided complete control of downy mildew. However, in the late 1980 s, failures of control by this fungicide were noticed in the field. Insensitivity of $B$. lactucae to metalaxyl was subsequently confirmed in the laboratory (43). This parallels the appearance of metalaxyl insensitivity that has occurred elsewhere in B. lactucae $(6,8)$ and other Oomycete pathogens $(25,44)$. Extensive sampling of B. lactucae in California determined that insensitivity had developed in the most prevalent pathotype present at the time (Pathotype IV), as well as in isolates of novel pathotype, and that insensitive isolates had rapidly spread to all major growing areas in the state (28). As a result, metalaxyl is ineffective and rarely applied.

The fungicides fosetyl-aluminum and maneb have been used since the failure of metalaxyl to control downy mildew. Maneb is a manganese ethylene bisdithiocarbamate (EBDC) fungicide; it has remained effective for over 40 years in the field, but because it is a contact fungicide, it provides incomplete control and is a preventative rather than curative control measure. Fosetyl-aluminum is a systemic fungicide that induces a resistance response in plants. Insensitivity to either of these fungicides in the field has not been confirmed previously. In 1997 and 1998, severe downy mildew was observed in fields treated with fosetyl-aluminum and/or maneb. The disease caused significant damage despite the repeated use of these fungicides. The possible development of B. lactucae strains insensitive to EBDC fungicides (Maneb, Manex, Amazin) and fosetyl-aluminum posed a significant threat to downy mildew management in California because these two fungicides are the primary disease control chemicals currently available. If these failures of control were due to the appearance of insensitive isolates, such strains would confound the evaluation of downy mildew prediction systems based on 
weather data that are being developed for timing fungicide applications (22-24).

Several foliar supplements containing phosphonic acid (also called phosphorous acid) are applied to commercial lettuce in California. These products are marketed as a source of phosphorus; however, they are converted to phosphite (phosphonate, $\mathrm{PO}_{3}{ }^{2}$ ) within the plant. Phosphite is also the active ingredient in fosetyl-aluminum and related fungicides (4). The widespread use of such nutritional supplements may have contributed to the development of insensitivity to fosetyl-aluminum over the 10 years preceding the recovery of insensitive isolates from Californian lettuce fields.

In this paper, we describe the characterization of isolates of B. lactucae collected in 1999 and 2000 that was conducted to determine whether the apparent failures of control in the field were due to insensitivity to fosetyl-aluminum and maneb, and the characterization of isolates collected in California over the 20 years preceding this collection to document the development of insensitivity. Our laboratory tests on seedlings and young plants demonstrated that some recently collected isolates are clearly much less sensitive to fosetyl-aluminum than isolates that had been collected earlier. Insensitivity to a phosphonic acidbased foliar supplement that contains the same active ingredient as fosetylaluminum paralleled insensitivity to fosetyl-aluminum. In contrast, insensitivity to maneb was not detected in our laboratory studies. Most insensitive isolates were Pathotype V, the most prevalent pathotype during this period. Quantitative assays of lesion number on older plants revealed that although some isolates sporulated after treatment with field doses of fosetylaluminum, the levels of disease were reduced. Consequently, fosetyl-aluminum may still have some utility in control of lettuce downy mildew.

\section{MATERIALS AND METHODS}

Collection and maintenance of isolates. Opportunistic samples of B. lactucae have been collected consistently over the past two decades in response to outbreaks of downy mildew in commercial fields (unpublished data). For this study, more intensive systematic surveys were conducted in 1999 and 2000; samples were collected regularly (monthly from April to September) from the primary growing regions in the Salinas Valley (Castroville, Chualar, Salinas, Soledad, and King City), Watsonville, and Santa Maria Valley regardless of disease levels. Each isolate was derived from a single lesion. For initial isolation, conidia were washed from lesions with distilled water, and the lesions were allowed to sporulate again at $15^{\circ} \mathrm{C}$. Conidia from the freshly sporulating lesions were used to inoculate 7-day-old seedlings of cv. Cobham Green, (containing no known $\mathrm{Dm}$ genes) as described previously (20). Seedlings were grown on Whatman filter paper in GA-7 Magenta boxes (Magenta Corp., Chicago, IL) with a nutrient solution (18) and incubated in an illuminated growth room $\left(15\right.$ to $17^{\circ} \mathrm{C}, 14-\mathrm{h}$ light period). After approximately 7 days, sporulation of B. lactucae was visible on the inoculated plants; these isolates were subsequently subcultured and maintained on seedlings as described previously (20,29).

Pathotype. The pathotype of each isolate was determined as described previously $(21,43)$. Suspensions of conidia were prepared from infected seedlings 7 to 9 days after inoculation by washing in distilled water. The suspension $\left(1 \times 10^{4}\right.$ conidia per $\mathrm{ml}$ ) was sprayed onto 7 -day-old seedlings of a differential set of 24 lettuce cultivars (approximately 20 seedlings per cultivar) selected to express each of the major known $D m$ genes $(14,21,43)$. At 7 , 14 , and 18 days after inoculation, seedlings were rated for the absence or presence of downy mildew sporulation and necrosis. The pathotype of each isolate was determined by its ability to sporulate on cultivars expressing each of the known $D m$ genes $(21,43)$.

Sexual compatibility type. The sexual compatibility type (SCT) of all field isolates was determined by culturing with isolates of the $\mathrm{B}_{1}$ and $\mathrm{B}_{2}$ SCTs as described previously $(21,43)$. At least 20 single cotyledons of cv. Cobham Green (no known $D m$ genes) were inoculated with either the test isolate alone to test for homothallism, or with the test isolate in combination with either the $\mathrm{B}_{1}$ or $\mathrm{B}_{2}$ type isolates (30). After 10 days, cotyledons were examined under the microscope for the presence of oospores. Those isolates capable of forming oospores with a $\mathrm{B}_{1}$ isolate were designated $\mathrm{B}_{2}$ and vice versa.

Insensitivity to fosetyl-aluminum and maneb. Routine tests for fungicide sensitivity/insensitivity were made using seedlings of cv. Cobham Green grown in 5-cm pots containing vermiculite. Approximately 10 to 15 seedlings were grown in each pot, spaced to avoid overlapping of leaves. Seedlings were sprayed with fungicide 7 to 10 days after sowing. Controlled doses of each fungicide were applied using an O'Brien linear sprayer that utilized the same nozzle as used in field applicators (O'Brien Industries, San Francisco, CA; now Technical Machining Inc., Sacramento, CA). This applicator is calibrated to distribute a dosage measurable in lb/acre and emulates the application of fungicides in the field.

We performed an initial study to establish dose-response curves for fosetylaluminum (Aliette, Rhone-Poulenc Ag. Co., Greensboro, NC) and maneb (Elf Atochem North America Inc., Philadelphia, PA). Fosetyl-aluminum was applied at $0,0.56,1.1,3.3,6.7,10.0,13.3$, and $17.8 \mathrm{~kg} / \mathrm{ha}$. The standard field rate is 3.3 $\mathrm{kg} / \mathrm{ha}$ (3 lb/acre or $6.75 \mathrm{~g}$ a.i./liter); we applied treatments at up to 10 times the field dose. Maneb was applied at 0, 0.55, $1.1,2.2,4.4,6.7,8.9$, and $11.0 \mathrm{~kg} / \mathrm{ha}$; the standard field rate is $2.2 \mathrm{~kg} / \mathrm{ha}$ ( $2 \mathrm{lb} / \mathrm{acre})$. Isolates IM25R7, a European isolate collected in 1976 and never exposed to fosetyl-aluminum in the field, and C980622, a California isolate collected in 1998 from a field exhibiting a failure of control, were used for the preliminary study and as the controls in subsequent assays. Based on this initial study, all 134 isolates collected in 1999 and 2000 were routinely assayed on seedlings treated with fosetyl-aluminum at $0,1.1,3.3$, and $6.7 \mathrm{~kg} / \mathrm{ha}$ or with maneb at $0,1.1,2.2$, and $4.4 \mathrm{~kg} /$ acre.

Seedlings were subsequently inoculated on the same day as the application of the fungicide spray. A spore suspension of $B$. lactucae $\left(10^{4}\right.$ conidia per $\left.\mathrm{ml}\right)$ was sprayed onto the seedlings after the fungicide had dried. After inoculation, the seedlings were maintained at $15^{\circ} \mathrm{C}$ in the growth room described above. Seedlings were scored for the percentage of seedlings with sporulation of $B$. lactucae 10,14 , and 18 days after inoculation. Tables 1, 2, and 3 report the highest sporulation rate; sporulation usually began in all treatments 5 to 6 days after inoculation, and usually there was no increase in the incidence of sporulation after 14 days. The level of insensitivity was scored on a four-point scale: $0=$ sensitive (S), $<15 \%$ of seedlings exhibiting sporulation at $3.3 \mathrm{~kg} / \mathrm{ha}$, no sporulation at 6.7 $\mathrm{kg} / \mathrm{ha} ; 1=$ partially sensitive (PS), 15 to $50 \%$ of seedlings exhibiting sporulation at $3.3 \mathrm{~kg} / \mathrm{ha},<25 \%$ exhibiting sporulation at $6.7 \mathrm{~kg} / \mathrm{ha} ; 2$ = partially insensitive (PI), 50 to $75 \%$ of seedlings exhibiting sporulation at $3.3 \mathrm{~kg} / \mathrm{ha}, 25$ to $50 \%$ exhibiting sporulation at $6.7 \mathrm{~kg} / \mathrm{ha} ; 3=$ insensitive (I), 75 to $100 \%$ of seedlings exhibiting sporulation at $3.3 \mathrm{~kg} / \mathrm{ha},>50 \%$ exhibiting sporulation at $6.7 \mathrm{~kg} / \mathrm{ha}$. In each set of assays, isolates IM25R7 and C980622 were included as sensitive and insensitive controls, respectively. Many of the isolates could only be assayed once due to the labor involved. Phenotypes of the control isolates, IM25R7 and C980622, were consistent throughout the study, and consequently the difference in fungicide insensitivity for these two isolates was replicated at least 100 times and remained constant over a period of 3 years. Assays of isolates C99S743, C99S744, C99S782, and C01S882 were also repeated at least five times per isolate over the course of the study. The phenotype of each of these isolates remained consistent in these assays.

Four isolates were assayed for fungicide insensitivity using older plants. The isolates assayed exhibited a range of insensitivities to fosetyl-aluminum and included the standard control isolates used in seedling assays. A larger number of isolates could not be assayed using older plants 
because of the space and labor required for such assays. In the first experiment, 6week-old plants of cv. Cobham Green (no known $D m$ genes) were used. In the second experiment, 6-week-old plants of cv. Salinas $(D m 5 / 8,7,13$ but susceptible to the isolates analyzed) were used. Six plants were used for each combination of isolate and treatment. Plants were treated with $0,1.1,3.3$, or $6.7 \mathrm{~kg} / \mathrm{ha}$ (a.i.) fosetyl aluminum as described for seedling assays. On the same day as the fungicide treatment, plants were inoculated with a spore suspension $\left(10^{4}\right.$ spores per $\left.\mathrm{ml}\right)$ of isolates IM25R7 (susceptible control), C980622 (insensitive control), C99S792 (partially sensitive), or C99S743 (insensitive) as described for seedling assays. Twelve to 14 days after inoculation, plants were evaluated for disease severity. The number of downy mildew lesions was determined for the seventh through twelfth leaves. It was assumed that the youngest six leaves were new growth that had not been exposed to the fungicide treatment or inoculum, and therefore these leaves were not assessed. A lesion was defined as the infected region delimited by the veins of the leaf. For statistical analysis, the maximum number of lesions per leaf was taken as 50, beyond which point it was difficult to determine the actual number of independent lesions. These older plant assays validated the use of seedlings for routine assays of isolates.

Insensitivity to phosphonic acid (Nutri-Phite). Nine isolates exhibiting a range of insensitivities to fosetyl-aluminum were assayed on seedlings using the method described above for assays of fosetylaluminum sensitivity with $0,2.3,4.6,6.9$, 9.2, and 11.4 liters/ha of a phosphonic acid supplement (Nutri-Phite: Biagro Western

Table 1. Number of isolates insensitive to fosetyl-aluminum relative to pathotype of Bremia lactucae

\begin{tabular}{|c|c|c|c|c|c|}
\hline \multirow[b]{2}{*}{ Pathotype $^{a}$} & \multicolumn{5}{|c|}{ Aliette response $^{\mathrm{b}}$} \\
\hline & $\mathbf{0}$ & 1 & 2 & 3 & Total \\
\hline CAV 4,18 & 4 & 11 & 9 & 24 & 48 \\
\hline Novel 18 & 1 & 8 & 11 & 16 & 36 \\
\hline Novel 4 & & 1 & 2 & 4 & 7 \\
\hline Novel 2,18 & & 3 & 2 & 2 & 7 \\
\hline Novel 15,18 & & & 1 & 4 & 5 \\
\hline Novel 2,15 & & & 1 & & 1 \\
\hline Novel 2,15,18 & 1 & 2 & 2 & 11 & 16 \\
\hline Novel 4,16,18 & & & 1 & 1 & 2 \\
\hline Novel 2,4,18 & & & & 3 & 3 \\
\hline Novel 3,18 & & 1 & & & 1 \\
\hline Novel 4,11,18 & 1 & & & & 1 \\
\hline Novel 4,15,18 & & 1 & & & 1 \\
\hline Novel 2,16,18 & & & & 1 & 1 \\
\hline Novel 2,4,15,18 & & 1 & 1 & & 2 \\
\hline Novel 2,3,4,15,18 & & & & 1 & 1 \\
\hline Novel $2,4,10,15,16,18$ & 1 & & & & 1 \\
\hline Novel 2,3,10,15,18 & 1 & & & & 1 \\
\hline Total & 9 & 28 & 30 & 67 & 134 \\
\hline
\end{tabular}

a Numbers indicate $\mathrm{Dm}$ resistance genes effective against the isolate.

${ }^{\mathrm{b}}$ Categories indicate level of insensitivity as determined on a four-point scale: $0=$ sensitive (S), $<15 \%$ of seedlings exhibiting sporulation at $3.3 \mathrm{~kg} / \mathrm{ha}$, no sporulation at $6.7 \mathrm{k} / \mathrm{ha} ; 1=$ partially sensitive (PS), 15 to $50 \%$ of seedlings exhibiting sporulation at $3.3 \mathrm{~kg} / \mathrm{ha},<25 \%$ exhibiting sporulation at 6.7 $\mathrm{kg} / \mathrm{ha} ; 2=$ partially insensitive (PI), 50 to $75 \%$ of seedlings exhibiting sporulation at $3.3 \mathrm{~kg} / \mathrm{ha}, 25$ to $50 \%$ exhibiting sporulation at $6.7 \mathrm{~kg} / \mathrm{ha} ; 3=$ insensitive (I), 75 to $100 \%$ of seedlings exhibiting sporulation at $3.3 \mathrm{~kg} / \mathrm{ha},>50 \%$ exhibiting sporulation at $6.7 \mathrm{~kg} / \mathrm{ha}$. In the absence of fungicide, sporulation was observed in $100 \%$ of cotyledons.

Table 2. Number of isolates insensitive to fosetyl-aluminum relative to their origin within the coastal lettuce growing areas of California

\begin{tabular}{lccccc}
\hline & \multicolumn{5}{c}{ Aliette response $^{\mathbf{a}}$} \\
\cline { 2 - 6 } Origin of isolate & $\mathbf{0}$ & $\mathbf{1}$ & $\mathbf{2}$ & $\mathbf{3}$ & Total \\
\hline Castroville & & 1 & 1 & 2 & 4 \\
Chualar & 1 & 1 & 4 & 9 & 11 \\
King City & 4 & 10 & 29 & 8 \\
Salinas & 3 & 11 & 3 & 13 & 37 \\
Santa Maria & & 1 & 10 & 14 \\
Soledad & 1 & 6 & & 2 & 9 \\
Watsonville & & & &
\end{tabular}

${ }^{\text {a }}$ Categories indicate level of insensitivity as determined on a four-point scale: $0=$ sensitive $(\mathrm{S}),<15 \%$ of seedlings exhibiting sporulation at $3.3 \mathrm{~kg} / \mathrm{ha}$, no sporulation at $6.7 \mathrm{k} / \mathrm{ha} ; 1=$ partially sensitive (PS), 15 to $50 \%$ of seedlings exhibiting sporulation at $3.3 \mathrm{~kg} / \mathrm{ha},<25 \%$ exhibiting sporulation at 6.7 $\mathrm{kg} / \mathrm{ha} ; 2=$ partially insensitive (PI), 50 to $75 \%$ of seedlings exhibiting sporulation at $3.3 \mathrm{~kg} / \mathrm{ha}, 25$ to $50 \%$ exhibiting sporulation at $6.7 \mathrm{~kg} / \mathrm{ha} ; 3=$ insensitive (I), 75 to $100 \%$ of seedlings exhibiting sporulation at $3.3 \mathrm{~kg} / \mathrm{ha},>50 \%$ exhibiting sporulation at $6.7 \mathrm{~kg} / \mathrm{ha}$. In the absence of fungicide, sporulation was observed in $100 \%$ of cotyledons.
Sales, Visalia, CA). The common field application rate is 3.4 to 4.6 liters/ha ( 3 to 4 pints/acre).

Insensitivity to metalaxyl. Lettuce cv. Cobham Green seedlings were grown in GA-7 Magenta boxes on Whatman paper with nutrient media (18) containing metalaxyl (Ridomil 2E: Ciba-Geigy Corp. Ag. Division, Greensboro, NC) at 0, 5, or $50 \mathrm{ppm}$ as described previously (43). One to five isolates were selected from each month's collection for analysis. A total of 30 7-day-old seedlings per isolate per treatment were inoculated using suspensions of conidia $\left(10^{4}\right.$ conidia per $\left.\mathrm{ml}\right)$, maintained in the $15^{\circ} \mathrm{C}$ growth room, and scored at 7, 11, and 15 days after inoculation for the presence of asexual sporulation. Sensitive control isolates only sporulated on seedlings grown in the absence of metalaxyl. Isolates that sporulated on seedlings grown with $50 \mathrm{ppm}$ metalaxyl (52.16 $\mathrm{mg} /$ liter), approximately 10 times the field rate, were considered insensitive (43).

\section{RESULTS}

Collection of isolates. A total of 134 isolates were collected in 1999 and 2000 from the coastal growing areas of California. In contrast to preceding years, disease was not prevalent during this period. A wide geographical range was sampled and isolates were collected from fields with

Table 3. Levels of fosetyl-aluminum insensitivity observed in isolates collected during different years in California

\begin{tabular}{lcc}
\hline Isolate & $\begin{array}{c}\text { Year of } \\
\text { collection }\end{array}$ & $\begin{array}{c}\text { Level of } \\
\text { insensitivity }\end{array}$ \\
\hline C83M47 & 1983 & 0 \\
C83P24 & 1983 & 0 \\
C90D08 & 1990 & 1 \\
C90D10 & 1990 & 1 \\
C90D24 & 1990 & 0 \\
C93D14 & 1993 & 0 \\
C93D36 & 1993 & 0 \\
C95A87 & 1995 & 2 \\
C95A84 & 1995 & 1 \\
C95A139 & 1995 & 2 \\
C95A148 & 1995 & 2 \\
C98O647 & 1998 & 2 \\
C980649 & 1998 & 1 \\
C98O671 & 1998 & 1 \\
C980672 & 1998 & 2 \\
C98O674 & 1998 & 3 \\
C980677 & 1998 & 3 \\
\hline
\end{tabular}

a Numbers indicate level of insensitivity as determined on a four-point scale: $0=$ sensitive (S), $<15 \%$ of seedlings exhibiting sporulation at $3.3 \mathrm{~kg} / \mathrm{ha}$, no sporulation at $6.7 \mathrm{k} / \mathrm{ha} ; 1=$ partially sensitive (PS), 15 to $50 \%$ of seedlings exhibiting sporulation at $3.3 \mathrm{~kg} / \mathrm{ha}$, $<25 \%$ exhibiting sporulation at $6.7 \mathrm{~kg} / \mathrm{ha} ; 2=$ partially insensitive (PI), 50 to $75 \%$ of seedlings exhibiting sporulation at $3.3 \mathrm{~kg} / \mathrm{ha}, 25$ to $50 \%$ exhibiting sporulation at $6.7 \mathrm{~kg} / \mathrm{ha} ; 3=$ insensitive (I), 75 to $100 \%$ of seedlings exhibiting sporulation at $3.3 \mathrm{~kg} / \mathrm{ha},>50 \%$ exhibiting sporulation at $6.7 \mathrm{~kg} / \mathrm{ha}$. In the absence of fungicide, sporulation was observed in $100 \%$ of cotyledons. 
both high and low incidence of disease (Tables 1 and 2). Additional details of the origin and characterization of all isolates are available in reports of the California Lettuce Research Board (31,32).

Pathotype. All isolates were characterized using the differential series of resistant cultivars, representing 18 characterized avirulence genes. The most common pathotypes were CAV and Novel 18 (Table $1)$. Of the 85 isolates collected in 1999 , $36 \%$ were CAV, $24 \%$ were Novel 18 , and the remaining $40 \%$ had various novel phenotypes. Of the 49 isolates collected in 2000, 23\% were pathotype CAV, 23\% were Novel 18, and the remaining $54 \%$ were of various novel phenotypes. Pathotypes I through IV that were predominant prior to 1990 were not detected (43). CAV isolates express only Avr4 and Avr18, and Novel 18 isolates only express Avrl8 of the characterized avirulence genes. Therefore, only Dm4 and Dm18 of the known resistance genes are effective against these isolates; however, some of the new sources of resistance that are currently under development are effective against these isolates (31). Novel isolates expressing a variety of other avirulence genes were also observed (Table 1).

Sexual compatibility type. Oospores were only detected in cultures with the $\mathrm{B}_{1}$ type isolate. Therefore, all isolates were of SCT $B_{2} . B_{1}$ and self-fertile isolates were not detected, consistent with findings from previous surveys of $B$. lactucae in California (43). There was therefore no evidence for the sexual cycle occurring in the California population characterized from commercial fields.

Insensitivity to fosetyl-aluminum. In the initial study to establish a doseresponse curve, two isolates were inoculated onto seedlings sprayed with $0,0.56$, $1.1,3.3,6.7,10.0,13.3$, and $17.8 \mathrm{~kg} / \mathrm{ha}$ fosetyl-aluminum; the recommended field rate is $3.3 \mathrm{~kg} / \mathrm{ha}$ ( $3 \mathrm{lb} / \mathrm{acre}$ ). This demonstrated that there were significant differences between the tested isolates in response to fosetyl-aluminum $(P<0.01$; Fig. 1). Isolate IM25R7, which had not been exposed to fosetyl-aluminum in the field, sporulated profusely at $0 \mathrm{~kg}$ fosetylaluminum per ha, sparsely at rates up to $3.3 \mathrm{~kg} / \mathrm{ha}$, and not at all at rates $3.3 \mathrm{~kg} / \mathrm{ha}$ and higher. However, isolate C980622 sporulated profusely on $100 \%$ of cotyledons at fosetyl-aluminum rates up to 3.3 $\mathrm{kg} / \mathrm{ha}$ and exhibited considerable sporulation at the higher rates as well. Infrequent sporulation of C980622 occurred at 17.8 $\mathrm{kg} / \mathrm{ha}$, which is five times greater than the recommended field rate. Consequently, all isolates were tested on seedlings sprayed with $0,1.1,3.3$, and $6.7 \mathrm{~kg} / \mathrm{ha}$ fosetylaluminum.

In the seedling assays for fungicide insensitivity, few of the isolates assayed were as sensitive as isolate IM25R7, and half of the isolates exhibited the highest level of insensitivity (Table 1). There was little variation among the isolates collected between the 2 years. In 1999, 7\% were as sensitive as isolate IM25R7, 27\% partially sensitive, $21 \%$ partially insensitive, and $45 \%$ insensitive to fosetyl-aluminum. In 2000 , $6 \%$ were sensitive, $10 \%$ partially sensitive, $25 \%$ partially insensitive, and $59 \%$ insensitive to fosetyl-aluminum. In all assays, the control isolate IM25R7 remained sensitive to the fungicide, and control isolate C980622 maintained a constant level of insensitivity to fosetylaluminum. Insensitivity was detected in all growing areas of California (Table 2). Insensitivity was observed in multiple pathotypes (Table 1).

In order to investigate when insensitivity to fosetyl-aluminum may have evolved, 17 isolates were retrieved from storage at $-80^{\circ} \mathrm{C}$ and tested on seedlings for fungicide insensitivity (Table 3). All isolates collected in or prior to 1993 were completely or partially sensitive to fosetylaluminum. Several California isolates were as sensitive as the European isolate IM25R7 that was collected in 1976. Isolates showed increasing levels of insensitivity between 1993 and 1998. Several isolates collected in 1995 were partially insensitive. The highest levels of insensitivity were not detected in isolates collected prior to 1998; this is consistent with the first observed failures of control in the field occurring in 1998.

To confirm that the insensitivity to fosetyl-aluminum observed was not an arti- fact of using young seedlings in our assays, four isolates exhibiting the range of fungicide sensitivities were assayed using older plants (Fig. 2). The relative sensitivities of these four isolates on 6-week-old plants paralleled their phenotypes determined in the seedling assays. This validated the routine use of seedling assays to assess insensitivity of large numbers of isolates to fosetyl-aluminum. While quantitative analysis of lesion number was not possible on seedlings (because infection was systemic rather than localized), such analysis on older plants revealed decreasing levels of disease with increasing levels of fungicide for all isolates. IM25R7 exhibited minimal sporulation on plants sprayed at $3.3 \mathrm{~kg} / \mathrm{ha}$. The isolates that exhibited high levels of insensitivity in the seedling assay, C980622 and C99S743, produced approximately $50 \%$ the number of lesions on plants sprayed at $3.3 \mathrm{~kg} / \mathrm{ha}$. Therefore, although considerable levels of disease occurred with high levels of inoculum $\left(1 \times 10^{4}\right.$ sporangia per $\left.\mathrm{ml}\right)$ and under conditions conducive to disease development, complete insensitivity (i.e., no decrease in disease in the presence of fungicide) to recommended field rates of fosetyl-aluminum was not detected.

Insensitivity to phosphonic acid. Seven California isolates and the two control isolates, IM25R7 and C980622, were assayed for insensitivity to the phosphonic acid-based foliar supplement, Nutri-Phite. The response of isolates on plants treated with phosphonic acid paralleled their

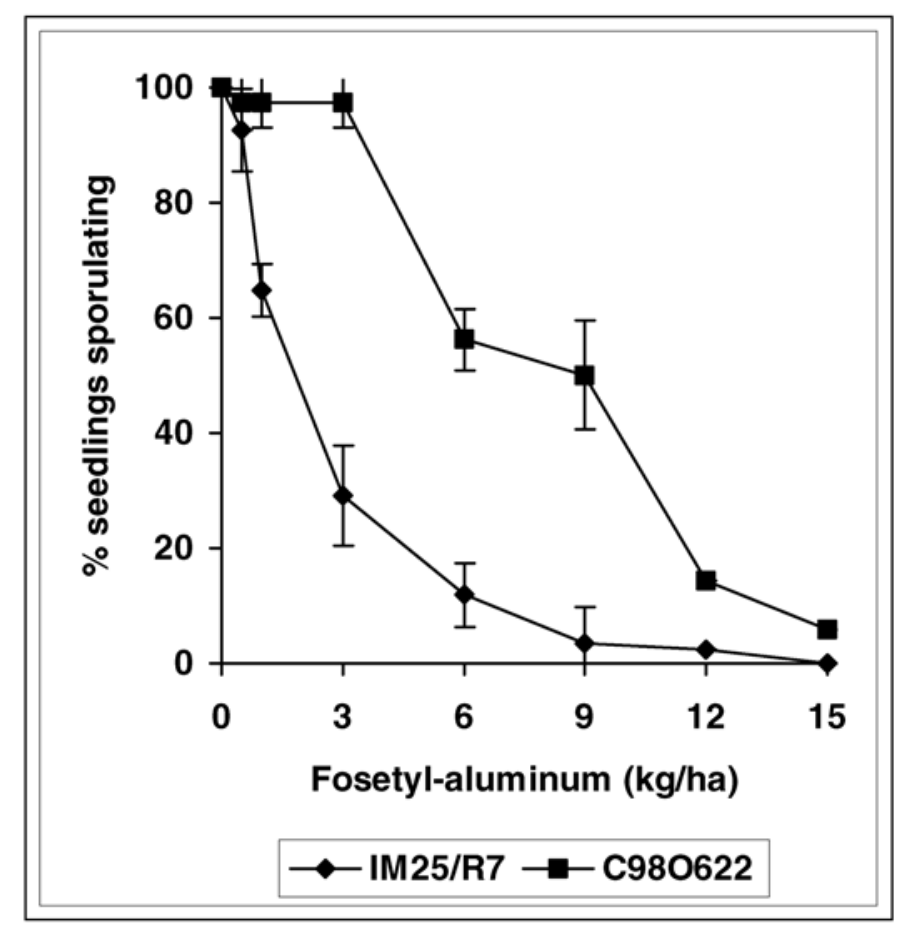

Fig. 1. Dosage response curve of two isolates of Bremia lactucae to seven concentrations of fosetylaluminum in seedling assays. Each combination of isolate and concentration was replicated three times. Error bars show standard errors. Field rates of 3.3 and $6.7 \mathrm{~kg} / \mathrm{ha}$ were selected to test other isolates for insensitivity. IM25R7 was used as the sensitive reference isolate and C980622 the insensitive reference isolate in all subsequent assays. 


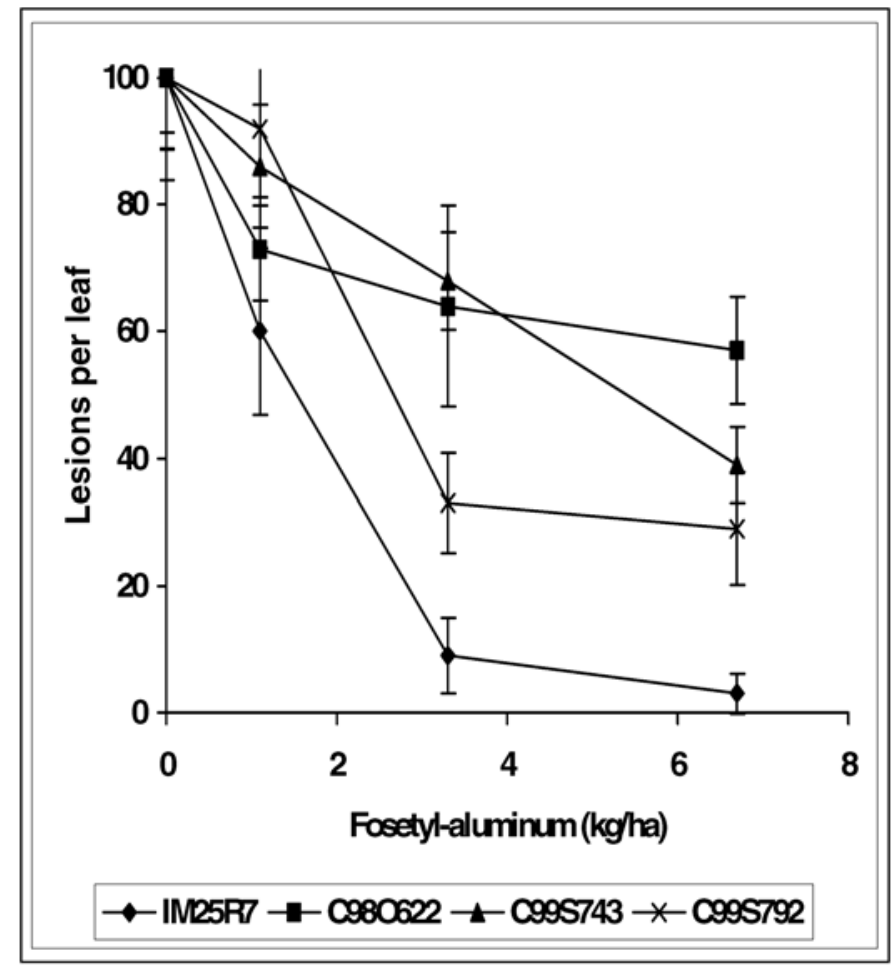

Fig. 2. Dosage response of four isolates of Bremia lactucae to fosetyl-aluminum in large plant assays expressed as percent decrease in total lesions per leaf. In prior seedling tests, IM25R7 was sensitive, C99S792 was partially insensitive, and C980622 and C99S743 were insensitive to fosetyl-aluminum. Each combination of isolate and concentration was replicated six times. Error bars show standard errors.

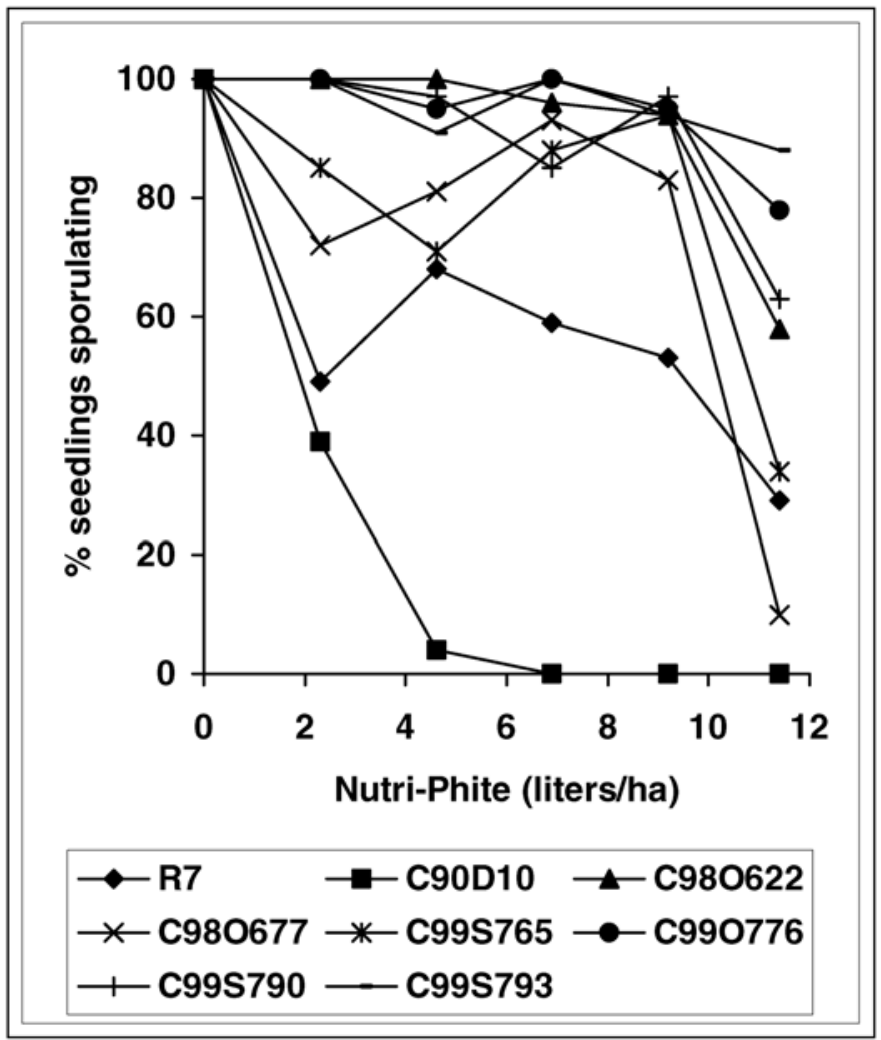

Fig. 3. Dosage response curve of eight isolates of Bremia lactucae to phosphonic acid in seedling assays. In prior assays, IM25R7 and C90D10 were sensitive and the remaining six isolates were insensitive to fosetyl-aluminum. Each combination of isolate and concentration was replicated three times. Standard errors (not shown) were similar to other experiments (Figs. 1 and 2) and ranged from 0 to 13.7 . response following treatments with fosetyl-aluminum (Fig. 3). The isolates that were sensitive to fosetyl-aluminum, IM25R7 and C90D10, exhibited little sporulation at the higher concentrations of phosphonic acid. All isolates tested that were insensitive to fosetyl-aluminum (C980622, C980677, C99S765, C990776, C99S790, C99S793) sporulated on seedlings treated with 4.6 liters/ha of phosphonic acid; $75 \%$ of isolates sporulated profusely ( $>80 \%$ of the sporulation in the control treatment) at a treatment rate of 9.2 liters/ha (Fig. 3).

Insensitivity to maneb. Control isolates (IM25R7 and C980622) were assayed for insensitivity to maneb at $0,0.56,1.1,2.2$, $4.4,6.7,8.9$, and $11 \mathrm{~kg} / \mathrm{ha}$, and standard rates for assays were established as $0,1.1$, 2.2 , and $4.4 \mathrm{~kg} / \mathrm{ha}$. The recommended field rate for maneb is $2.2 \mathrm{~kg} / \mathrm{ha}$ ( $2 \mathrm{lb} / \mathrm{acre})$. All isolates characterized at this time were found to be sensitive to this fungicide, including those collected from fields where an apparent failure of control by maneb had been previously observed. All isolates were sensitive to maneb. Some isolates sporulated infrequently ( 1 to 2 seedlings per assay) at the lower rates of maneb. These isolates were subcultured from the sporulating seedlings and re-assayed individually. None sporulated on maneb at any treatment level.

Insensitivity to metalaxyl. To investigate whether there was any association between insensitivity to different fungicides, a sample of isolates that were collected in 1999 (10 isolates) and 2000 (20 isolates) were also assayed for sensitivity to metalaxyl. All 30 isolates that exhibited a range of sensitivity to fosetyl-aluminum sporulated profusely on seedlings grown in nutrient medium containing $50 \mathrm{ppm}$ metalaxyl and were therefore insensitive to metalaxyl. Therefore, there was no evidence of association between insensitivity to these two fungicides.

\section{DISCUSSION}

Our data clearly demonstrate the existence of insensitivity to fosetyl-aluminum in B. lactucae. Laboratory tests showed the widespread occurrence of insensitivity to this fungicide among California isolates collected from commercial fields in 1999 and 2000. Among 134 isolates collected from the coastal growing areas, there were clear differences in sensitivity to this fungicide when assayed on lettuce seedlings; approximately half the isolates were insensitive to twice the recommended field application rate. Representative insensitive isolates were also insensitive to a phosphonic acid-based foliar supplement that is used widely on commercial lettuce crops. In addition, all isolates tested were insensitive to metalaxyl.

Prior reports of field isolates of phytopathogens that were insensitive to fosetylaluminum have been rare. Fosetyl- 
aluminum insensitivity in Phytophthora cinnamomi infecting the ornamental Chamaecyparis lawsoniana was reported in France (45); however, no further examples of field insensitivity have been observed. Metalaxyl-insensitive isolates of Phytophthora infestans infecting potato in Israel also showed insensitivity to fosetylaluminum when treated with $64 \mathrm{mg}$ per pot of the active compound (5). This rate is comparable to the field rate of $6.7 \mathrm{~g}$ a.i./liter applied in our experiments. However, in neither case were insensitive isolates widespread and persistent, in contrast to the situation of insensitivity in B. lactucae in California.

Low levels of insensitivity to fosetylaluminum have been induced in the laboratory by mutagenesis of several oomycete pathogens. Encysted zoospores of P. capsici from pepper (2) and tomato (15), $P$. palmivora from cacao (12), $P$. parasitica var. nicotianae from tobacco (15), and Pythium aphanidermatum from turf (38) were mutagenized and selected on media containing up to $100 \mu \mathrm{g} / \mathrm{ml} \mathrm{H}_{3} \mathrm{PO}_{3}$ (phosphonic acid). In planta assays of the mutants utilized treatments of fosetylaluminum ( 0.9 to $1.6 \mathrm{~g}$ a.i./liter) that were much lower than the rates used in our studies. The highest rate of insensitivity in planta was observed in $P$. palmivora, where $10 \%$ of plants treated with 1.6 $\mathrm{g} /$ liter (a.i.) fosetyl-aluminum survived (12). Based on these laboratory studies, it had been predicted that insensitivity to fosetyl-aluminum might develop in $B$. lactucae $(4,36)$. However, until the current study, insensitivity had not been observed.

All isolates of B. lactucae assayed were sensitive to maneb at half the recommended field rate. Despite the apparent failure of maneb applications to control downy mildew in the field, insensitivity to this fungicide was not detected under laboratory conditions. Whether this reflects a lack of insensitivity to the fungicide, the conditions of the assay, or the instability of the phenotype during asexual culture prior to analysis is not known. Insensitivity to EBDC fungicides has rarely been reported since their discovery in 1943 (16). Failures of maneb to control Botrytis squamosa on onion in New York fields (26) and of Dithane M-45 to control Venturia inaequalis on apple in India (9) have been attributed to insensitivity. Metalaxylinsensitive isolates of Pseudoperonospora cubensis from cucumber in Israel showed insensitivity when sprayed with mancozeb (37). Mancozeb-insensitive isolates of Helminthosporium halodes, a pathogen of sugarcane, have been induced in the laboratory (35). Given the above instances of insensitivity to EBDC fungicides and the flexibility of the B. lactucae population, it would not be surprising to find variation in the sensitivity of $B$. lactucae to maneb in the future. It was not, however, detected in the present study.
Historically, lettuce downy mildew has been controlled by a combination of resistant cultivars and chemical applications. $B$. lactucae has responded by evolving to render each control measure ineffective. The evolution of insensitivity to fosetylaluminum is the latest event in this cycle. Insensitive isolates were found throughout the California growing region, covering over 200 miles. Fungicide-insensitive isolates have become a common component of the California population of B. lactucae. Although there is evidence of increased variation in pathotype, the $\mathrm{B}_{1}$ sexual compatibility type was not detected in the current survey. Therefore, there is no evidence that the sexual cycle is generating variation in commercial fields.

Fosetyl-aluminum remained effective for the more than 20 years since widespread applications started in 1978. Isolates with insensitivity to fosetylaluminum were first detected in 1998 in parallel with apparent failures of control in the field. All of the fosetyl-aluminum insensitive isolates tested were also insensitive to treatments with phosphonic acid as anticipated due to the presence of similar active ingredients in these two formulations (4). It is possible that applications of plant growth supplements containing phosphonic acid accelerated the development of fosetyl-aluminum insensitivity, particularly if they exposed the population of $B$. lactucae to sublethal doses of the active ingredients of fosetyl-aluminum.

There are limited options currently available for fungicidal control of lettuce downy mildew. Maneb continues to be useful; however, it is only effective as a preventative rather than curative treatment and has a long (14 day) preharvest interval that is difficult to maintain in a fastgrowing crop such as lettuce. Metalaxyl remains registered for lettuce in California; however, our current data confirm that insensitivity to this fungicide is still widespread in the coastal growing areas. Copper-based fungicides are also registered but in general are ineffective at controlling the disease and tend to leave unacceptable residues on the crop as well as at times causing phytotoxicity $(17,33)$. The new generation of fungicides that induce the host defense system, such as benzothiadiazole (BTH), have yet to be approved for lettuce. Therefore, the development of insensitivity to fosetyl-aluminum poses a severe threat to downy mildew management in California.

Fosetyl-aluminum insensitivity was observed in multiple pathotypes; therefore, there is not the opportunity to integrate the deployment of known $\mathrm{Dm}$ genes with applications of fosetyl-aluminum to control all California isolates. However, some of the new sources of resistance are currently effective against all isolates tested. No doubt these will succumb over time to new pathotypes of B. lactucae. Because viru- lent variants tend to arise from the predominant pathotype, the continued use of fosetyl-aluminum will influence whether such new virulent variants are insensitive to this fungicide and consequently whether fosetyl-aluminum may become routinely effective once again. However, this assumes that insensitivity to fosetylaluminum would decline in the absence of routine use. The insensitivity of the control isolate C980622 remained stable in the absence of selection during at least 100 asexual generations of subculture during this study.

The laboratory data from older plants may explain the inconsistencies of control experienced with field applications of fosetyl-aluminum. Laboratory assays of insensitivity using older plants under ideal conditions for infection and disease development demonstrated that no isolate was completely insensitive to fosetylaluminum. At field rates, the number of lesions was reduced by half in isolates that were scored as insensitive in seedling assays, although the level of disease on these plants remained high. In the field, applications of fosetyl-aluminum may provide adequate levels of control under conditions not conducive to epidemics of downy mildew. However, when conditions favor downy mildew epidemics, many isolates would be expected to cause significant levels of disease in spite of applications of fosetyl-aluminum. Disease severity may be even greater in the absence of fungicide. Therefore, under heavy disease pressure, failures of control can be expected in the field. However, under low inoculum pressure, fosetyl-aluminum may provide observable levels of protection.

There is the potential to develop a disease forecasting system to aid in the informed applications of fungicides. However, the insensitivity to fosetyl-aluminum has important consequences to both the validation of a forecasting system and the use of fosetyl-aluminum as a component in the control strategy. The current disease prediction models attempt to forecast infection periods based on selected weather variables such as leaf wetness periods (42). These will potentially enable growers to reduce spray applications and reduce the fungicide load on crops $(22,23)$. However, the model is designed to predict downy mildew infection periods and then schedule fungicide treatment. The presence of insensitive isolates greatly compromises the possibility to evaluate the prediction system; a disease control failure could be attributed to model inadequacies, infection by insensitive isolates, or both. Even if the model is robust, its utility is limited until there are effective fungicides available.

The occurrence of B. lactucae isolates insensitive to fosetyl-aluminum as well as metalaxyl raises the question of crossresistance; however, there are no data to support this possibility (27). There is a 
lack of consensus on whether crossresistance actually occurs between different classes of fungicides $(2,3)$. Crossresistance has been suggested for metalaxyl and propamocarb, metalaxyl and Cyprofuram + folpet, metalaxyl and fosetyl-aluminum, metalaxyl and mancozeb, and benzimidazole fungicides and fosetylaluminum $(5,13,37,38)$. However, evidence for cross-resistance may be lacking, and cross-resistance was not detected between phenylamides and nonrelated fungicides (11). Additional studies are needed to determine whether the B. lactucae isolates in the Salinas Valley are demonstrating crossresistance between diverse chemical groups or showing independent multiple resistance to the fungicides; given that metalaxyl insensitivity evolved before fosetyl-aluminum insensitivity, the latter is more likely.

In the future, we will continue to monitor the distribution of insensitive isolates in California to examine the stability of the insensitivity phenotype in the field if the use of fosetyl-aluminum declines.

\section{ACKNOWLEDGMENTS}

We gratefully acknowledge the financial support of the California Lettuce Research Board (CLRB), Alf-Atochem, Griffin Corporation, and RhonePoulenc. We thank P. Barbree, B. Bassi, T. Benedict, S. Boutry, K. Dunster, H. Faulkner, T. Gonzales, D. Grissom, M. Hardoy, D. Haviland, V. Heintzberger, D. Henderson, L. Kerr, E. Mora, D. Ouimette, P. Iverson, T. Luther, N. Philips, E. Roncoroni, S. Riba, C. Thomas, B. Waycott, R. Whitson, and K. Zeise for help in collecting isolates and technical assistance. We thank E. Kurtz, A. Paulus, R. Mercer, and the CLRB Pest Management Subcommittee for helpful discussions regarding lettuce downy mildew.

\section{LITERATURE CITED}

1. Anonymous. 2001. California Agricultural Facts. California Department of Food and Agriculture. Online publication.

2. Bower, L. A., and Coffey, M. D. 1985. Development of laboratory tolerance to phosphorous acid, fosetyl-Al, and metalaxyl in Phytophthora capsici. Can. J. Plant Pathol. 7:1-6.

3. Clerjeau, M., Moreau, C., Piganeau, B., Bompeix, G., and Malfatti, P. 1984. Effectiveness of fosetyl-Al against strains of Plasmopara viticola and Phytophthora infestans that have developed resistance to anilide fungicides. Proc. 1984 Br. Crop Prot. Conf.-Pests Dis. 2:497-502.

4. Coffey, M. D., and Ouimette, D. G. 1989. Phosphonates: Antifungal compounds against Oomycetes. Pages 107-129 in: Nitrogen, Phosphorus, and Sulphur Utilization by Fungi. L. Boddy, R. Marchant, and D. J. Read, eds. Cambridge University Press, Cambridge, England.

5. Cohen, Y., and Samoucha, Y. 1984. Crossresistance to four systemic fungicides in metalaxyl-resistant strains of Phytophthora infestans and Pseudoperonospora cubensis. Plant Dis. 68:137-139.

6. Crute, I. R. 1987. The occurrence, characteristics, distribution, genetics, and control of a metalaxylresistant pathotype of Bremia lactucae in the United Kingdom. Plant Dis. 71:763-767.

7. Crute, I. R. 1992. The role of resistance breeding in the integrated control of downy mildew (Bremia lactucae) in protected lettuce. Euphytica 63:95-102

8. Crute, I. R., Norwood, J. M., and Gordon, P. L.
1987. The occurrence, characteristics and distribution in the United Kingdom of resistance to phenylamide fungicides in Bremia lactucae (lettuce downy mildew). Plant Pathol. 36:297315.

9. Dar, G. N., Puttoo, B. L., and Gani, M. Y. 1981. Ineffectiveness of Dithane M-45 against Venturia inaequalis causing apple scab disease in Kashmir. Abstr. 3rd Int. Sympos. Plant Pathol., New Delhi. pp. 98-99.

10. Davis, R. M., Subbarao, K. V., Raid, R. N., and Kurtz, E. A. 1997. Compendium of Lettuce Diseases. American Phytopathological Society, St. Paul, MN.

11. Diriwachter, G., Sozzi, D., Ney, C., and Staub, T. 1987. Cross-resistance in Phytophthora infestans and Plasmopara viticola against different phenylamides and unrelated fungicides. Crop Prot. 6:250-255

12. Dolan, T. E., and Coffey, M. D. 1988. Correlative in vitro and in vivo behavior of mutant strains of Phytophthora palmivora expressing different resistances to phosphorous acid and fosetyl-Na. Phytopathology 78:974-978.

13. Faretra, F., Pollastro, S., and Sansiviero, F. 1992. Activity of adjuvants in Aliette against Botryotinia fuckeliana (Botrytis cinerea) and their cross-resistance with benzimidazole fungicides. Pestic. Sci. 35:171-174.

14. Farrara, B. F., Ilott, T. W., and Michelmore, R. W. 1987 Genetic analysis of factors for resistance to downy mildew (Bremia lactucae) in species of lettuce (Lactuca sativa). Plant Pathol. 36:499-514.

15. Fenn, M. E., and Coffey, M. D. 1989. Quantification of phosphonate and ethyl phosphonate in tobacco and tomato tissues and significance for the mode of action of two phosphonate fungicides. Phytopathology 79:76-82.

16. Fry, W. E. 1982. Principles of Plant Disease Management. Academic Press, New York. pp. 166-168, 279-280.

17. Garcia, A., Baquedano, F. J., Navarro, P., and Castillo, F. J. 1999 Oxidative stress caused by copper in sunflower plants. Free Radical Res. 31(suppl.):S45-S50.

18. Hewitt, E. J. 1952 Sand and water culture methods used in the study of plant nutrition. Technical communication of the Commonwealth Bureau of Horticulture and Plantation Crops, East Malling, Maidstone, Kent.

19. Hulbert, S. H., and Michelmore, R. W. 1988. DNA restriction fragment length polymorphism and somatic variation in the lettuce downy mildew fungus, Bremia lactucae. Mol. Plant-Microbe Interact. 1:17-24.

20. Ilott, T. W., Durgan, M. E., and Michelmore, R. W. 1987. Genetics of virulence in California populations of Bremia lactucae (lettuce downy mildew). Phytopathology 77:1381-1386.

21. Ilott, T. W., Hulbert, S. H., and Michelmore, R. W. 1989. Genetic analysis of the gene-for-gene interaction between lettuce (Lactuca sativa) and Bremia lactucae. Phytopathology 79:888-897.

22. Koike, S. T., and Henderson, D. M. 1997. Implementation of a downy mildew prediction model. California Iceberg Lettuce Advisory Board Annual Report: 1996-1997.

23. Koike, S. T., and Henderson, D. M. 1998. Implementation of a downy mildew prediction model: 2nd year. California Lettuce Research Board Annual Report: 1997-1998.

24. Koike, S. T., and Henderson, D. M. 1999. Implementation of a downy mildew prediction model: 3rd year. California Lettuce Research Board Annual Report: 1998-1999.

25. Lee, T. Y., Mitzubuti, E., and Fry, W. E. 1999. Genetics of metalaxyl resistance in Phytophthora infestans. Fungal Genet. Biol. 26:118-130.

26. Lorbeer, J. W., and Ellerbrock, L. A. 1976. Failure of ethylene bisdithiocarbamates to control Botrytis leaf blight of onion. Proc. Am. Phytopathol. Soc. 3:75-84.
27. Lyr, H. 1995. Modern Selective Fungicides: Properties, Applications, Mechanisms of Action. 2nd ed. Gustav Fischer Verlag. New York.

28. Michelmore, R. W. 1990. Insensitivity to Ridomil in lettuce downy mildew. California Iceberg Lettuce Research Board Annual Report: 1989-1990.

29. Michelmore, R. W., Ilott, T., Hulbert, S. H., and Farrara, B. 1988. Genetics of virulence. The Downy Mildews. Pages 53-79 in: The Genetics of Phytopathogenic Fungi. G. S. Sidhu, P. H. Williams, and D. S. Ingram, eds. Advances in Plant Pathology, Vol. 6. Academic Press, New York.

30. Michelmore, R. W., and Ingram, D. S. 1982. Secondary homothallism in Bremia lactucae. Trans. Br. Mycol. Soc. 78:1-9.

31. Michelmore, R. W., Ochoa, O. E., and Koike, S. T. 2000. Fungicide insensitivity in lettuce downy mildew. California Lettuce Board Annual Report: 1999-2000. Online publication.

32. Michelmore, R. W., Ochoa, O. E., and Koike, S. T. 2001. Fungicide insensitivity in lettuce downy mildew. California Lettuce Board Annual Report: 2000-2001. Online publication.

33. Ouariti, O., Boussania, N., Barrouk, M., Cherif, A., and Ghorbal, M. H. 1997. Cadmium- and copper-induced changes in tomato membrane lipids. Phytochemistry 45:13431350

34. Paulus, A. O., Vilchez, M., and Laemmlen, F. 1998. Control of downy mildew of lettuce with fungicides. California Lettuce Research Board Annual Report: 1997-1998.

35. Peddi Reddy, K., and Anilkumar, T. B. 1987. Stability and fitness of mancozeb-resistant strains of Helminthosporium halodes. Zentralbl. Mikrobiol. 142:535-540.

36. Raid, R. N., and Datnoff, L. E. 1990. Loss of the EBDC fungicides: Impact on control of downy mildew of lettuce. Plant Dis. 74:829831.

37. Samoucha, Y., and Cohen, Y. 1984. Differential sensitivity to mancozeb of metalaxyl-sensitive and metalaxyl-resistant isolates of Pseudoperonospora cubensis. Phytopathology 74:14371439

38. Sanders, P. L., Coffey, M. D., Greer, G. D., and Soika, M. D. 1990. Laboratory-induced resistance to fosetyl-Al in a metalaxyl-resistant field isolate of Pythium aphanidermatum. Plant Dis. 74:690-692.

39. Scherm, H., Koike, S. T., Laemmlen, F. F., and van Bruggen, A. H. C. 1995. Field evaluation of fungicide spray advisories against lettuce downy mildew (Bremia lactucae) based on measured or forecast morning leaf wetness. Plant Dis. 79:511-516.

40. Scherm, H., and van Bruggen, A. H. C. 1994. Effects of fluctuating temperatures on the latent period of lettuce downy mildew (Bremia lactucae). Phytopathology 84:853-859.

41. Scherm, H., and van Bruggen, A. H. C. 1994. Weather variables associated with infection of lettuce by downy mildew (Bremia lactucae) in coastal California. Phytopathology 84:860-865.

42. Scherm, H., and van Bruggen, A. H. C. 1995 Concurrent spore release and infection of lettuce by Bremia lactucae during mornings with prolonged leaf wetness. Phytopathology 85:552-555

43. Schettini, T. M., Legg, E. J., and Michelmore, R. W. 1991. Insensitivity to metalaxyl in California populations of Bremia lactucae and resistance of California lettuce cultivars to downy mildew. Phytopathology 81:64-70.

44. Shattock, R. C. 1988. Studies on the inheritance of resistance to metalaxyl in Phytophthora infestans. Plant Pathol. 87:4-11.

45. Vegh, I., Leroux, P., Le Berre, A., and Lanen, C. 1985. Detection on Chamaecyparis lawsoniana 'Ellwoodii' of a strain of Phytophthora cinnamomi resistant to fosetyl-Al. Rev. Hortic. 262:19-21. 